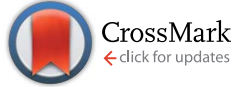

Cite this: RSC Adv., 2016, 6, 102343

Received 25th August 2016

Accepted 18th October 2016

DOI: $10.1039 / c 6 r a 21383 a$

www.rsc.org/advances

\section{Induction of smectic polymorphism in bent-core derivatives of the 6-oxoverdazyl by partial fluorination of alkyl chains $\uparrow$}

\author{
Sylwia Ciastek, ${ }^{a}$ Piotr Kaszyński, ${ }^{\text {*abc }}$ Damian Pociecha ${ }^{d}$ and Marcin Jasiński ${ }^{a}$ \\ A series of bent-core mesogens $2[m, n]$ derived from the 6 -oxoverdazyl radical and containing partially \\ fluorinated alkyl tails was prepared and investigated by thermal, optical, XRD and EPR methods. In \\ contrast to non-fluorinated analogs, the series $2[m, n]$ exhibits SmA and SmC phases with thermal \\ stability dependent on the degree of fluorination and the $F / H$ ratio $(m / n)$ in the alkyl chain.
}

\section{Introduction}

With the increasing number and variety of all-organic paramagnetic liquid crystals ${ }^{1}$ the focus is shifting towards optimization of their properties for specific applications. Materials based on $\pi$-delocalized radicals are of particular interest in the context of molecular electronics and spintronics ${ }^{2}$ due to their photophysical and electrochemical properties. ${ }^{3}$ In this context we have been working with 6-oxoverdazyl and demonstrated that it is a suitable paramagnetic structural element for disc-like ${ }^{4-9}$ and bent-core, such as $\mathbf{1}[n]$ (Fig. 1), ${ }^{\mathbf{1 0 1 1}}$ liquid crystalline materials. The latter compounds exhibit ambipolar photoconductivity, electro-optical effects, a novel Tet $_{3 \mathrm{D}}$ phase, ${ }^{10}$ and their electronic absorption covers the visible region of the spectrum depending on the substituent at the $\mathrm{C}(3)$ position. ${ }^{11}$ The bent-core mesogens $\mathbf{1}[\boldsymbol{n}]$ typically exhibit a nematic phase. For electronic applications, however, more organized lamellar phases with close intermolecular contacts are necessary. As the first step towards this goal we have focused on fluorofobic ${ }^{12}$ interactions to induce nanosegregation. ${ }^{13}$ In this context we have investigated a series of mesogens $2[\boldsymbol{m}, \boldsymbol{n}]$ bearing partially fluorinated alkyl chains (Fig. 1).

Here we discuss the synthesis, thermal and optical investigation of series $2[\boldsymbol{m}, \boldsymbol{n}]$, and analysis of mesophases by powder XRD and EPR methods.

${ }^{a}$ Faculty of Chemistry, University of Eódź, Tamka 12, 91-403 Eódź, Poland. E-mail: piotrk@cbmm.lodz.pl

${ }^{b}$ Organic Materials Research Group, Centre of Molecular and Macromolecular Studies, Polish Academy of Sciences, Sienkiewicza 112, 90-363 Eódź, Poland

'Department of Chemistry, Middle Tennessee State University, Murfreesboro, TN, 37130, USA

${ }^{d}$ Department of Chemistry, University of Warsaw, Żwirki $i$ Wigury 101, 02-089 Warsaw, Poland

$\dagger$ Electronic supplementary information (ESI) available. See DOI: 10.1039/c6ra21383a

\section{Results and discussion}

\section{Synthesis}

6-Oxoverdazyl derivatives $2[\boldsymbol{m}, \boldsymbol{n}]$ were obtained in yields $57-82 \%$ by esterification of diphenols 3 with appropriate 4-alkoxybenzoyl chlorides $4[m, n]$ in the presence of DMAP (Scheme 1). The diphenol precursors 3 were obtained using the general Milcent protocol ${ }^{14}$ following functional group transformations, ${ }^{15}$ as described recently. ${ }^{11}$ The required benzoyl chlorides $4[m, n]$ were prepared from the corresponding 4 alkoxybenzoic acids ${ }^{16}$ and $\mathrm{SOCl}_{2}$.

\section{Thermal analysis}

Optical microscopy and DSC analysis revealed that all derivatives in series $2[\boldsymbol{m}, \boldsymbol{n}]$ exhibit liquid crystalline behavior, with the exception of 2[6,4]a (Table 1). Thus, all mesogens form a SmA phase, while in derivatives $2[m, n] \mathbf{a}\left(\mathrm{X}=\mathrm{CF}_{3}\right)$ also a monotropic SmC phase was detected by optical microscopy (Fig. 2 and 3) and confirmed by powder XRD (vide infra). This is in sharp contrast with behavior found in the non-fluorinated series $\mathbf{1}[n]$ : only the shortest member of the $1[n] \mathbf{a}$ series, derivative $\mathbf{1}[8] \mathbf{a}$,

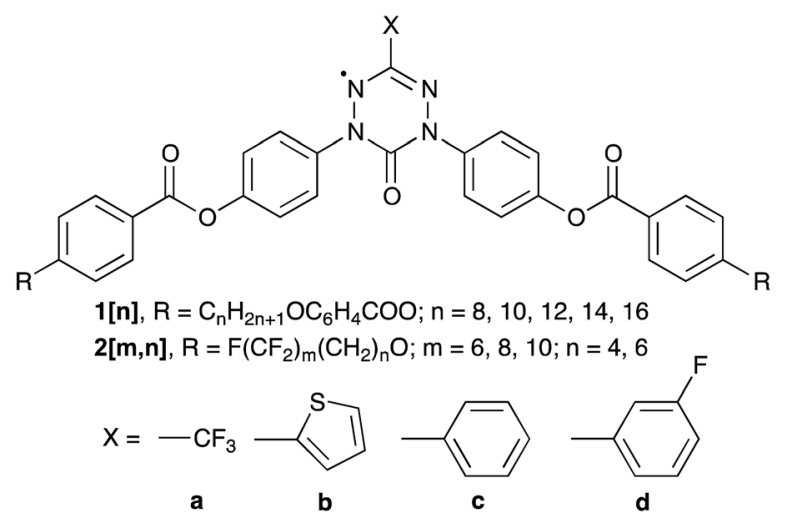

Fig. 1 The structures of bent-core 6 -oxoverdazyls $1[n]$ and $2[m, n]$. 
<smiles>[X]C1=NN(c2ccc(O)cc2)C(=O)N(c2ccc(O)cc2)N1</smiles>

Scheme 1 Preparation of 6-oxoverdazyls 2[m,n]. Reagents and conditions: (i) $\mathrm{F}\left(\mathrm{CF}_{2}\right)_{m}\left(\mathrm{CH}_{2}\right)_{n} \mathrm{OC}_{6} \mathrm{H}_{4} \mathrm{COCl}(4[m, n]), \mathrm{DMAP}, \mathrm{CH}_{2} \mathrm{Cl}_{2}$, rt.

exhibits a monotropic SmA phase, ${ }^{10}$ while other derivatives show nematic and tetragonal phases or no mesogenic behavior at all $(\mathbf{1}[n] \mathbf{b} \text { and } \mathbf{1}[n] \mathbf{c})^{.^{10,11}}$ Thus, it appears that removal of the $-\mathrm{C}_{6} \mathrm{H}_{4} \mathrm{COO}-$ group and partial fluorination of the alkoxy chain in $\mathbf{1}[\boldsymbol{n}]$ is an effective tool for induction of a broad-range mesogenic behavior in 6-oxoverdazyls $2[\boldsymbol{m}, \boldsymbol{n}]$ irrespectively on the nature of substituent $\mathrm{X}$ at the $\mathrm{C}(3)$ position. For example, while the thien-2-yl derivative $\mathbf{1}[\mathbf{1 2}] \mathbf{b}$ melts at $153{ }^{\circ} \mathrm{C}$ and has a virtual $\mathrm{N}-\mathrm{I}$ transition $\left(\left[T_{\mathrm{NI}}\right]\right)$ at $138{ }^{\circ} \mathrm{C},{ }^{11}$ the fluorocarbon analogue 2[6,6]b exhibits a SmA phase between $107{ }^{\circ} \mathrm{C}$ and $197^{\circ} \mathrm{C}$ (Table 1).

Analysis of data in Table 1 demonstrates that the mesophase stability strongly depends on the size of the semirigid perfluoroalkane segment. For instance, increasing the number of the $\mathrm{CF}_{2}$ units from 6 to 8 induces smectic behavior in $2[8,4]$ a, and additional two $\mathrm{CF}_{2}$ units increase SmA and SmC phase stability by about $30 \mathrm{~K}$ in $2[\mathbf{1 0 , 4}] \mathbf{a}$ with a modest increase of melting temperature. Similar behavior is observed in the pair $2[6,6] \mathbf{a}$ and $2[8,6] \mathbf{a}$ in which elongation of the fluorocarbon by two units results in stabilization of the SmA phase by nearly $60 \mathrm{~K}$.

Data in Table 1 also permits analysis of the effect of the degree of alkyl chain fluorination on transition temperatures. Thus, increasing the number of fluorine atoms or changing the $\mathrm{F} / \mathrm{H}$ ratio in the $\mathrm{C}_{12}$ chain from $1: 1$ in $2[6,6] \mathbf{a}$ to $2: 1$ in $2[8,4] \mathbf{a}$ increases the SmA-I transition temperature by $59 \mathrm{~K}$. In another pair with the $\mathrm{C}_{14}$ tail $(2[\mathbf{8 , 6}] \mathbf{a}$ and $2[\mathbf{1 0}, \mathbf{4}] \mathbf{a})$, changing the $\mathrm{F} / \mathrm{H}$ ratio from $4: 3$ to $5: 2$ increases SmA phase stability by $34 \mathrm{~K}$.

Table 1 Thermal properties of $2[m, n]^{a}$

\begin{tabular}{|c|c|c|c|c|}
\hline Compound & $\left(\mathrm{CF}_{2}\right)_{m}$ & $\left(\mathrm{CH}_{2}\right)_{n}$ & $\mathrm{X}$ & Transition temperatures $/{ }^{\circ} \mathrm{C}$ \\
\hline $2[6,4] \mathrm{a}$ & 6 & 4 & $\mathrm{CF}_{3}$ & Cr 156 I \\
\hline $2[6,6] \mathrm{a}$ & 6 & 6 & $\mathrm{CF}_{3}$ & Cr $132(\text { SmC } 75 \text { SmA 91) })^{b}$ I \\
\hline $2[8,4] \mathrm{a}$ & 8 & 4 & $\mathrm{CF}_{3}$ & Cr $127(\text { SmC } 108)^{b}$ SmA 150 I \\
\hline $2[8,6] \mathrm{a}$ & 8 & 6 & $\mathrm{CF}_{3}$ & Cr $124(\text { SmC } 116)^{b}$ SmA 149 I \\
\hline $2[10,4] \mathrm{a}$ & 10 & 4 & $\mathrm{CF}_{3}$ & Cr $144(\operatorname{SmC} 137)^{b}$ SmA 183 I \\
\hline $2[6,6] \mathrm{b}$ & 6 & 6 & Th & Cr 107 SmA $197 \mathrm{I}^{c}$ \\
\hline $2[8,4] \mathrm{b}$ & 8 & 4 & Th & Cr $129 \operatorname{SmA} 245 \mathrm{I}^{c, d}$ \\
\hline $2[10,4] \mathrm{b}$ & 10 & 4 & Th & $\mathrm{Cr} 136 \mathrm{SmA} \sim 220 \mathrm{I}^{c, d}$ \\
\hline $2[6,6] c$ & 6 & 6 & $\mathrm{Ph}$ & Cr 135 SmA 183 I \\
\hline $2[6,6] d$ & 6 & 6 & $3-\mathrm{FC}_{6} \mathrm{H}_{4}$ & Cr 147 SmA 192 I \\
\hline
\end{tabular}

${ }^{a} \mathrm{Cr}=$ crystal, $\mathrm{SmA}=$ smectic $\mathrm{A}, \mathrm{SmC}=$ smectic $\mathrm{C}, \mathrm{I}=$ isotropic. Typical heating rate $10 \mathrm{~K} \mathrm{~min}^{-1} .{ }^{b}$ Monotropic transition. Temperatures from XRD analysis. ${ }^{c}$ Decomposition. ${ }^{d}$ Heating rate $35 \mathrm{~K} \mathrm{~min}^{-1}$.

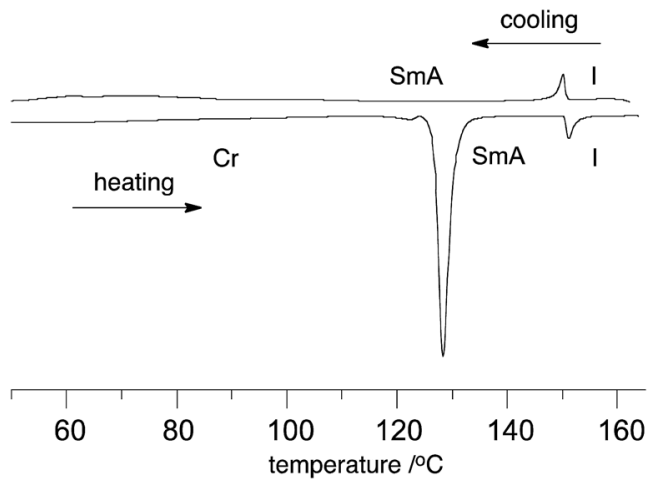

Fig. 2 A DSC trace of 2[8,4]a; heating/cooling rates are $10 \mathrm{~K} \mathrm{~min}^{-1}$.

Finally a comparison of derivatives in series $2[6,6]$ demonstrates that the effectiveness of the $\mathrm{C}(3)-\mathrm{X}$ substituent in stabilization of the SmA follows the order $\mathrm{CF}_{3}<\mathrm{C}_{6} \mathrm{H}_{5}<\mathrm{C}_{6} \mathrm{H}_{4} \mathrm{~F}-m$ $<2$-thienyl, which is different from that established for the virtual $\mathrm{N}-\mathrm{I}$ transition temperature in series $\mathbf{1}[\mathbf{1 2}]:^{11} 2$-thienyl < $\mathrm{CF}_{3}<\mathrm{C}_{6} \mathrm{H}_{5}<\mathrm{C}_{6} \mathrm{H}_{4} \mathrm{~F}-m$. This stark difference in the position of the 2-thienyl substituent in the two series suggests that other molecular factors, such as the $\pi-\pi$ interactions, are important in the stabilization of the nematic and smectic phases.

\section{Powder XRD analysis}

XRD analysis confirmed the presence of a SmA phase in all mesogenic compounds in series $2[\boldsymbol{m}, \boldsymbol{n}]$ and a SmC phase in derivatives $2[\boldsymbol{m}, \boldsymbol{n}] \mathbf{a}$ (see the ESI, $\dagger$ and X-ray diffractogram for 2[8,4]a in Fig. 4). All compounds exhibit a typical layer thickness dependence on temperature: it increases in SmA phase and then decreases in the SmC phase with decreasing temperature. Analysis of the thermal expansion coefficient $\kappa$, obtained by fitting the datapoints to a quadratic function $d_{01}=\kappa T^{2}+b$, demonstrates that the layer thickness change depends on the substituent at the $\mathrm{C}(3)$ position: it is similar for the aryl groups and twice larger for
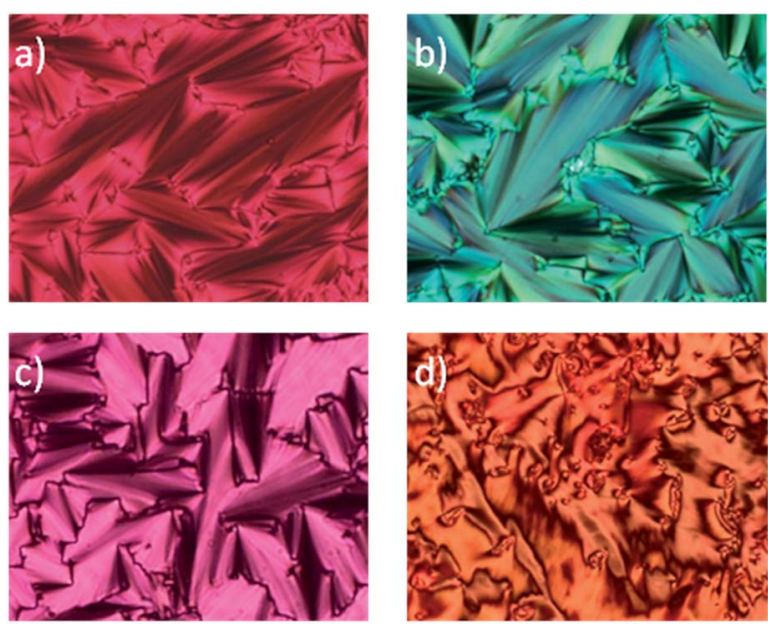

Fig. 3 Optical textures of a SmA phase in 2[6,6]c (a), 2[6,6]b (b), 2[8,6]a (c), and a schlieren texture of a SmC phase in 2[8,6]a (d; without top cover) obtained on slow cooling from the isotropic phase. 


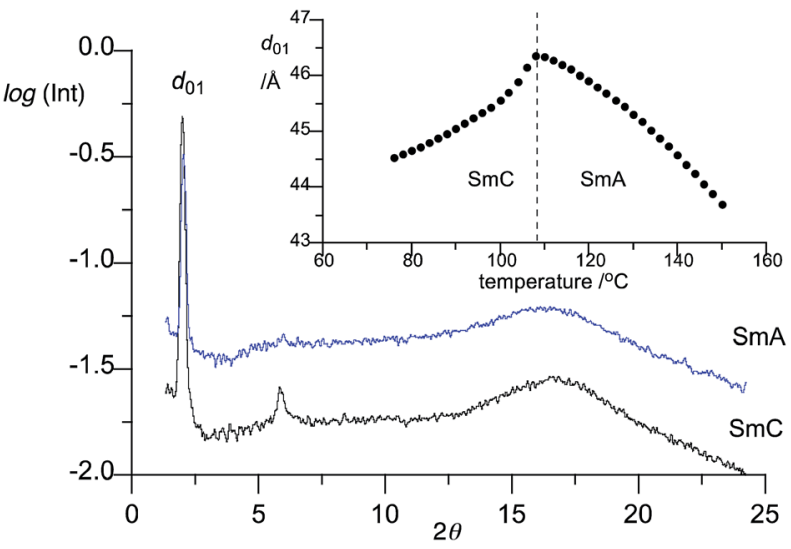

Fig. $4 \mathrm{X}$-ray diffractogram for SmA and SmC phases of 2[8,4]a at $140{ }^{\circ} \mathrm{C}$ and $100{ }^{\circ} \mathrm{C}$, respectively, obtained by integration of the $2 \mathrm{D}$ patterns. The insert shows temperature dependence of the $d_{01}$ signal.

the $\mathrm{CF}_{3}$ group and follows the order: 2-thienyl $<\mathrm{C}_{6} \mathrm{H}_{5} \sim \mathrm{C}_{6} \mathrm{H}_{4} \mathrm{~F}-m$ $<\mathrm{CF}_{3}$ (Table 2). This indicates that derivatives $2[\boldsymbol{m}, \boldsymbol{n}] \mathbf{a}$ undergo the most substantial molecular reorganization in the SmA phase presumably due to the bulk of the $\mathrm{CF}_{3}$ substituent. Conversely, least reorganization in the SmA phase is observed in the thienyl derivative $2[\mathbf{6}, \mathbf{6}] \mathbf{b}$, which coincides with its highest SmA-I transition temperature in the series (Table 1).

Data in Table 2 also suggests that the higher degree of fluorination in the alkyl tail (longer $R_{\mathrm{f}}$ component or higher $F / H$ ratio) the stronger temperature effect on the layer thickness.

A comparison of the layer thickness with DFT-calculated molecular size indicates a partial (up to $20 \%$ ) interdigitation of the molecules in the SmA phase as shown for $2[6,6] \mathbf{b}$ in Fig. 5 .

The typical lack of intralayer molecular correlation in the observed SmA and SmC phases is consistent with no photoconductivity observed in a sample of $2[8,4] \mathbf{a}$.

\section{EPR analysis}

In contrast to standard SQUID magnetometry, EPR spectroscopy provides information on local spin-spin interactions in

Table 2 Layer spacing $d_{01}$, molecular length $L$, degree of interdigitation $I$, and thermal expansion coefficient $\kappa$

\begin{tabular}{|c|c|c|c|c|c|}
\hline \multirow[b]{2}{*}{ Compound } & \multicolumn{4}{|l|}{ SmA } & \multirow{2}{*}{$\frac{\mathrm{SmC}}{d_{01}{ }^{e} / \AA}$} \\
\hline & $d_{01}{ }^{a} / \AA$ & $L^{b} / \AA$ & $I^{c} / \%$ & $\kappa^{d} / \mathrm{pm} \mathrm{K}^{-2}$ & \\
\hline $2[6,6] \mathrm{a}$ & 45.07 & 54.14 & 17 & -0.031 & 43.27 \\
\hline $2[8,4] \mathrm{a}$ & 44.57 & 53.46 & 17 & -0.026 & 45.56 \\
\hline $2[8,6] \mathrm{a}$ & 47.11 & 57.93 & 19 & -0.039 & 47.99 \\
\hline $2[10,4] \mathrm{a}$ & 47.18 & 58.66 & 20 & -0.033 & 50.18 \\
\hline $2[6,6] \mathrm{b}$ & 44.75 & 53.97 & 17 & -0.015 & - \\
\hline $2[6,6] \mathrm{c}$ & 44.28 & 53.99 & 18 & -0.017 & - \\
\hline $2[6,6] d$ & 44.30 & 53.99 & 18 & -0.017 & - \\
\hline
\end{tabular}

${ }^{a}$ Layer spacing measured at $T=T_{\mathrm{AI}}-10 \mathrm{~K} .{ }^{b}$ The length of the molecule measured as the $\mathrm{F} \cdots \mathrm{F}$ distance. ${ }^{c}$ Degree of interdigitation $I=\left(L-d_{01}\right) /$ $L{ }^{d}$ Thermal expansion coefficient for the SmA phase from the fitting the $\kappa T^{2}+b$ function. See the ESI. ${ }^{e}$ Layer spacing measured at $T=T_{\mathrm{AC}}$ $-6 \mathrm{~K}$.

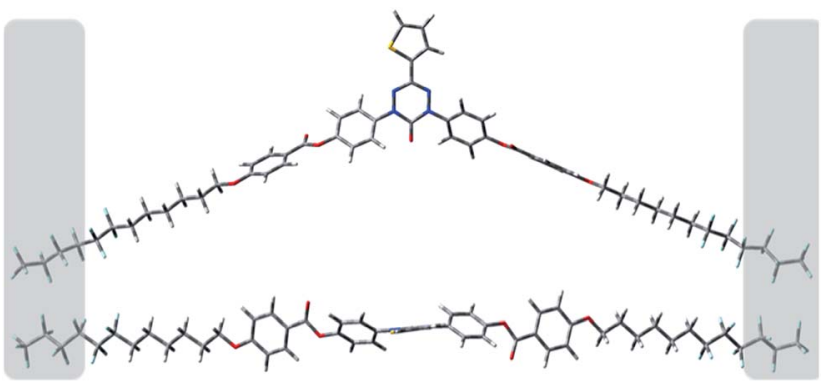

Fig. 5 Two views of 2[6,6]b modelled at the B3LYP/6-31G* level of theory. The shaded areas suggest interdigitated parts of the molecule.

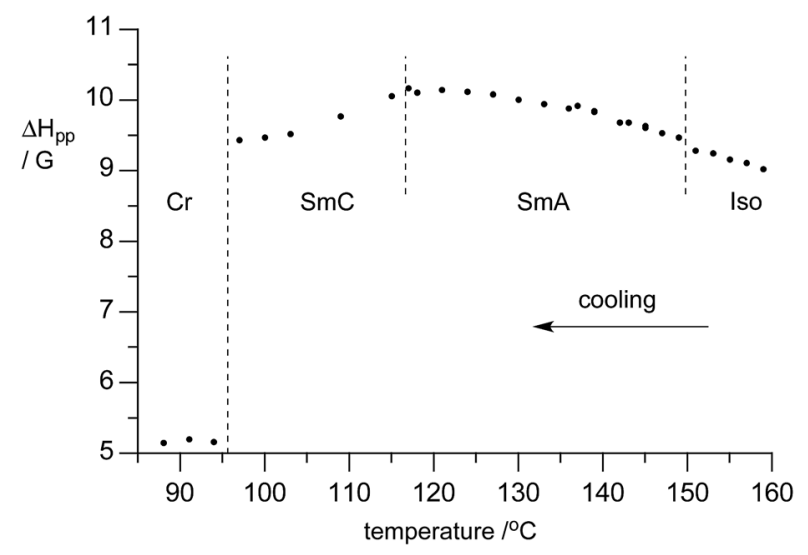

Fig. 6 EPR line width as a function of temperature recorded for neat $2[8,6] a$ on cooling.

a greater temperature range and is suitable for studying of high temperature paramagnetic liquid crystals, ${ }^{17}$ such as series $2[\boldsymbol{m}, \boldsymbol{n}]$. Thus, analysis of $2[\mathbf{8}, \mathbf{6}] \mathbf{a}$ demonstrated a monotonic broadening of the single line EPR spectrum with decreasing temperature resulting from increasing spin-spin exchange interactions in the neat isotropic phase (Fig. 6). At the I-SmA transition increased molecular organization in the lamellar structure results in a subtle increase of the line width $\left(\Delta H_{\mathrm{pp}}\right)$. Maximum line width is observed for the SmA phase just before the SmA-SmC transition at $116{ }^{\circ} \mathrm{C}$ at which the phase has the highest order. In the SmC phase the line width, $\Delta H_{\mathrm{pp}}$, decreases due to progressing molecular tilt and changing spin-spin exchange interactions. At $96{ }^{\circ} \mathrm{C}$ the monotropic $\mathrm{SmC}$ phase crystallizes abruptly changing the strength of spin-spin interactions between the paramagnetic centres in the rigid crystalline phase. Thus, the variable temperature EPR spectroscopy offers a convenient tool for analysis of molecular organization in fluid phases. ${ }^{17}$

\section{Conclusions}

Partial fluorination of the alkyl chains in bent-core derivatives of 6-oxoverdazyl $\mathbf{1}[\boldsymbol{n}]$ induced SmA and SmC behavior in series $2[\boldsymbol{m}, \boldsymbol{n}]$; unfortunately, more organized lamellar phases desired for electronic applications were not observed. The mesophase stability in the series depends on the degree of alkyl chain 
fluorination, and increases with increasing size of the perfluoroalkyl segment.

Variable temperature EPR was demonstrated to be a useful tool in studying of local spin-spin interactions as a function of the phase structure. The search for banana phases in the 6oxoverdazyl derivatives with intralayer molecular correlation continues.

\section{Computational details}

Quantum-mechanical calculations were carried out using Gaussian 09 suite of programs..$^{18}$ Geometry optimizations for unconstrained molecules at the pseudo- $C_{2}$ symmetry were undertaken at the B3LYP/6-31G* level of theory using default convergence limits.

\section{Experimental section}

\section{General}

Solvents and reagents were purchased and used as received without further purification. Products were purified by flash chromatography on silica gel (230-400 mesh, Merck or Fluka). IR spectra were measured in $\mathrm{KBr}$ pellets with a FT-IR NEXUS spectrometer. Mass spectrometry was performed with a Finnigan MAT-95 or a Varian 500-MS LC Ion Trap instrument. Thermal analysis was performed with differential scanning calorimeter DSC-1 Mettler Toledo and onset temperatures are reported in Table 1.

X-ray diffraction experiments in the wide-angle range were performed with Bruker D8 GADDS system, and Bruker Nanostar system was used for small angle diffraction measurements.

Variable temperature EPR spectra for neat radical $2[8,6] \mathbf{a}$ were recorded using an X-band Bruker spectrometer every 2-3 K on cooling allowing for 2 min stabilization. The line width was measured as a difference in position of the maximum and minimum of the EPR signal.

If not stated otherwise, reactions were carried out under argon in a flame-dried flask with addition of the reactants via syringe; subsequent manipulations were conducted in air.

The synthesis of diphenols 3 was reported recently. ${ }^{11}$

Synthesis of 6-oxoverdazyls $2[m, n]$. A mixture of diphenol 3 $(0.23 \mathrm{mmol})$ and freshly prepared appropriate acid chloride $4[\boldsymbol{m}, \boldsymbol{n}](0.57 \mathrm{mmol})$ in dry $\mathrm{CH}_{2} \mathrm{Cl}_{2}(5 \mathrm{~mL})$ containing DMAP ( $84 \mathrm{mg}, 0.69 \mathrm{mmol}$ ) was stirred at room temperature until the diphenol and the intermediate mono-acylated derivative were fully consumed (about 20-30 min). The mixture was quenched with $\mathrm{H}_{2} \mathrm{O}$, and the products extracted with $\mathrm{CH}_{2} \mathrm{Cl}_{2}(3 \times 10 \mathrm{~mL})$. The organic layers were dried $\left(\mathrm{MgSO}_{4}\right)$, and the solvents were removed under reduced pressure. The resulting crude product was purified by chromatography followed by repeated recrystallization. Reported yields refer to analytically pure samples.

1,5-Bis $\{4-[4-(5,5,6,6,7,7,8,8,9,9,10,10,10$-tridecafluoro-decyloxy)benzoyloxy]phenyl $\}$-3-trifluoromethyl-6-oxoverdazyl (2[6,4]a). Crude product was purified by column chromatography $\left(\mathrm{SiO}_{2}, \mathrm{CH}_{2} \mathrm{Cl}_{2} /\right.$ petroleum ether $2: 1)$ followed by recrystallization $\left(\mathrm{CH}_{3} \mathrm{CN}, 3 \times\right)$ to yield $215 \mathrm{mg}(70 \%)$ as wine-red crystals: $\mathrm{IR}(\mathrm{KBr}) \nu 1734(\mathrm{C}=\mathrm{O})$, 1606, 1512, 1498 (C=C), 1256, 1201, 1165, 1144 (C-F), 1067 (C-O) $\mathrm{cm}^{-1}$; MALDI-MS ( $\left.\mathrm{m} / \mathrm{z}\right): 1311.3\left(100,[\mathrm{M}-\mathrm{CO}]^{+}\right)$. Anal. calcd for $\mathrm{C}_{49} \mathrm{H}_{32} \mathrm{~F}_{29} \mathrm{~N}_{4} \mathrm{O}_{7}$ : C, 43.93; H, 2.41; N, 4.18. Found: $\mathrm{C}, 44.01 ; \mathrm{H}$, $2.45 ; \mathrm{N}, 4.07$.

1,5-Bis $\{4-[4-(5,5,6,6,7,7,8,8,9,9,10,10,11,11,12,12,12$-heptadecafluorododecyloxy)benzoyloxy]phenyl\}-3-trifluoromethyl-6-oxoverdazyl $(2[8,4] a)$. Crude product was purified by column chromatography $\left(\mathrm{SiO}_{2}, \mathrm{CH}_{2} \mathrm{Cl}_{2} /\right.$ petroleum ether $\left.2: 1\right)$ followed by recrystallization $\left(\mathrm{CH}_{3} \mathrm{CN}, 3 \times\right)$ to yield $231 \mathrm{mg}(66 \%)$ as orange crystals: $\mathrm{IR}(\mathrm{KBr}) \nu$ 1729 (C=O), 1607, 1511 (C=C), 1257, 1205, $1167(\mathrm{C}-\mathrm{F}) \mathrm{cm}^{-1}$; MALDI-MS $(m / z): 1511.3\left(100,[\mathrm{M}-\mathrm{CO}]^{+}\right)$. Anal. calcd for $\mathrm{C}_{53} \mathrm{H}_{32} \mathrm{~F}_{37} \mathrm{~N}_{4} \mathrm{O}_{7}: \mathrm{C}, 41.34 ; \mathrm{H}, 2.09 ; \mathrm{N}, 3.64$. Found: $\mathrm{C}, 41.42 ; \mathrm{H}, 2.07$; $\mathrm{N}, 3.46$.

1,5-Bis $\{4-[4-(5,5,6,6,7,7,8,8,9,9,10,10,11,11,12,12,13,13,14,14,14-$ henicosafluorotetradecyloxy)benzoyloxy]phenyl $\}$-3-trifluoromethyl-6oxoverdazyl $(2[10,4] a)$. Crude product was purified by column chromatography $\left(\mathrm{SiO}_{2}, \mathrm{CH}_{2} \mathrm{Cl}_{2} /\right.$ petroleum ether $1: 1$ gradient $3: 1)$ followed by recrystallization $\left(\mathrm{CH}_{3} \mathrm{CN}, 5 \times\right)$ to yield $173 \mathrm{mg}$ $(58 \%)$ as orange crystals: MALDI-MS $(\mathrm{m} / \mathrm{z})$ : $1711.1(100$, $\left.[\mathrm{M}-\mathrm{CO}]^{+}\right)$. Anal. calcd for $\mathrm{C}_{57} \mathrm{H}_{32} \mathrm{~F}_{45} \mathrm{~N}_{4} \mathrm{O}_{7}: \mathrm{C}, 39.35 ; \mathrm{H}, 1.85 ; \mathrm{N}$, 3.22. Found: $\mathrm{C}, 39.34 ; \mathrm{H}, 2.10 ; \mathrm{N}, 2.99$.

1,5-Bis $\{4$-[4-(7,7,8,8,9,9,10,10,11,11,12,12,12-tridecafluorododecyloxy)benzoyloxy]phenyl\}-3-trifluoromethyl-6-oxoverdazyl $(2[6,6] a)$. Crude product was purified by column chromatography $\left(\mathrm{SiO}_{2}, \mathrm{CH}_{2} \mathrm{Cl}_{2} /\right.$ petroleum ether $\left.2: 1.5\right)$ followed by recrystallization $\left(\mathrm{AcOEt} / \mathrm{CH}_{3} \mathrm{CN}, 1: 4\right.$ and AcOEt/pentane, $1: 4$; $3 \times)$ to yield $205 \mathrm{mg}(63 \%)$ as orange crystals: IR $(\mathrm{KBr}) \nu 1733$ $(\mathrm{C}=\mathrm{O}), 1606,1511(\mathrm{C}=\mathrm{C}), 1254,1068(\mathrm{C}-\mathrm{O}), 1203,1166,1146$ (C-F), 1068 (C-O) cm ${ }^{-1}$; MALDI-MS (m/z): 1367.4 (100, $[\mathrm{M}-\mathrm{CO}]^{+}$). Anal. calcd for $\mathrm{C}_{53} \mathrm{H}_{40} \mathrm{~F}_{29} \mathrm{~N}_{4} \mathrm{O}_{7}: \mathrm{C}, 45.60 ; \mathrm{H}, 2.89 ; \mathrm{N}$, 4.01. Found: C, 45.89; H, 3.14; N, 3.88.

1,5-Bis $\{4-[4-(7,7,8,8,9,9,10,10,11,11,12,12,13,13,14,14,14$-heptadecafluorotetradecyloxy)benzoyloxy]phenyl\}-3-trifluoromethyl-6oxoverdazyl $(2[8,6] a)$. Crude product was purified by column chromatography $\left(\mathrm{SiO}_{2}, \mathrm{CH}_{2} \mathrm{Cl}_{2} /\right.$ petroleum ether $\left.2: 1\right)$ followed by recrystallization $\left(\mathrm{CH}_{3} \mathrm{CN}, 3 \times\right)$ to yield $260 \mathrm{mg}(72 \%)$ as orange crystals: $\mathrm{IR}(\mathrm{KBr}) \nu 1729(\mathrm{C}=\mathrm{O}), 1607,1510(\mathrm{C}=\mathrm{C})$, 1255, 1205, 1150, 1167 (C-F), $1074(\mathrm{C}-\mathrm{O}) \mathrm{cm}^{-1}$; MALDI-MS (m/ $z)$ : $1567.6\left(100,[\mathrm{M}-\mathrm{CO}]^{+}\right)$. Anal. calcd for $\mathrm{C}_{57} \mathrm{H}_{40} \mathrm{~F}_{37} \mathrm{~N}_{4} \mathrm{O}_{7}: \mathrm{C}$, 42.90; H, 2.59; N, 3.51. Found: C, 42.98; H, 2.48; N, 3.24.

1,5-Bis $\{4-[4-(7,7,8,8,9,9,10,10,11,11,12,12,12$-tridecafluorododecyloxy)benzoyloxy]phenyl $\}$-3-thien-2-yl-6-oxoverdazyl $(2[\mathbf{6}, \mathbf{6}] \mathbf{b})$. Crude product was purified by column chromatography $\left(\mathrm{SiO}_{2}\right.$, $\mathrm{CH}_{2} \mathrm{Cl}_{2} /$ hexane $10: 1$ ) followed by recrystallization (AcOEt/ pentane, $1: 5$ and $\left.\mathrm{AcOEt} / \mathrm{CH}_{3} \mathrm{CN}, 1: 5 ; 4 \times\right)$ to yield $175 \mathrm{mg}$ $(62 \%)$ as dark green crystals: $\mathrm{IR}(\mathrm{KBr}) \nu 1734(\mathrm{C}=\mathrm{O}), 1607,1511$ $(\mathrm{C}=\mathrm{C}), 1257(\mathrm{C}-\mathrm{O})$, 1204, 1166, 1145 (C-F), 1069 (C-O) cm ${ }^{-1}$; MALDI-MS $(\mathrm{m} / \mathrm{z})$ : $1381.1\left(100,[\mathrm{M}-\mathrm{CO}]^{+}\right)$. Anal. calcd for $\mathrm{C}_{56} \mathrm{H}_{43} \mathrm{~F}_{26} \mathrm{~N}_{4} \mathrm{O}_{7} \mathrm{~S}: \mathrm{C}, 47.70 ; \mathrm{H}, 3.07$; N, 3.97. Found: C, 47.77; H, $3.27 ; \mathrm{N}, 3.68$.

1,5-Bis $\{4-[4-(5,5,6,6,7,7,8,8,9,9,10,10,11,11,12,12,12$-heptadecafluorododecyloxy)benzoyloxy]phenyl\}-3-thien-2-yl-6-oxoverdazyl $(2[8,4] b)$. Crude product was purified by column chromatography $\left(\mathrm{Al}_{2} \mathrm{O}_{3}\right.$, petroleum ether/AcOEt $10: 1$ gradient $\left.3: 1\right)$ followed by recrystallization $\left(\mathrm{CH}_{2} \mathrm{Cl}_{2} /\right.$ pentane, $\left.1: 6 ; 5 \times\right)$ to yield $190 \mathrm{mg}(60 \%)$ as green crystals; IR $(\mathrm{KBr}) \nu 1736(\mathrm{C}=\mathrm{O}), 1692$, 1609, 1511 (C=C), 1261 (C-O), 1207, 1166, 1147 (C-F), 1074 (CO) $\mathrm{cm}^{-1}$; MALDI-MS $(\mathrm{m} / \mathrm{z}): 1525.2\left(100,[\mathrm{M}-\mathrm{CO}]^{+}\right)$. Anal. calcd 
for $\mathrm{C}_{56} \mathrm{H}_{35} \mathrm{~F}_{34} \mathrm{~N}_{4} \mathrm{O}_{7} \mathrm{~S}$ : C, 43.28; $\mathrm{H}, 2.27 ; \mathrm{N}, 3.61$. Found: $\mathrm{C}, 43.20$; $\mathrm{H}, 2.20 ; \mathrm{N}, 3.34$.

1,5-Bis $\{4-[4-(5,5,6,6,7,7,8,8,9,9,10,10,11,11,12,12,13,13,14,14,14-$ henicosafluorotetradecyloxy)benzoyloxy]phenyl $\}$-3-thien-2-yl-6oxoverdazyl $(2[10,4] b)$. Crude product was purified by column chromatography $\left(\mathrm{Al}_{2} \mathrm{O}_{3}\right.$, petroleum ether/AcOEt $10: 1$ gradient $3: 1)$ followed by recrystallization $\left(\mathrm{CH}_{2} \mathrm{Cl}_{2} /\right.$ pentane, $1: 4$ and $\left.\mathrm{CH}_{2} \mathrm{Cl}_{2} / \mathrm{CH}_{3} \mathrm{CN}, 1: 4 ; 5 \times\right)$ to yield $150 \mathrm{mg}(57 \%)$ as green crystals: IR (KBr) $\nu 1733(\mathrm{C}=\mathrm{O}), 1695,1609,1513(\mathrm{C}=\mathrm{C}), 1255$ (C-O), 1211, 1166, 1154 (C-F), 1071 (C-O) cm ${ }^{-1}$; MALDI-MS $(\mathrm{m} / \mathrm{z}): \quad 1725.2 \quad\left(100, \quad[\mathrm{M}-\mathrm{CO}]^{+}\right)$. Anal. calcd for $\mathrm{C}_{60} \mathrm{H}_{35} \mathrm{~F}_{42} \mathrm{~N}_{4} \mathrm{O}_{7} \mathrm{~S}: \mathrm{C}, 41.09 ; \mathrm{H}, 2.01 ; \mathrm{N}, 3.19 ; \mathrm{S}, 1.83$. Found: $\mathrm{C}$, 41.05; H, 2.27; N, 3.03; S, 1.99 .

1,5-Bis $\{4-[4-(7,7,8,8,9,9,10,10,11,11,12,12,12$-tridecafluorododecyloxy)benzoyloxy]phenyl\}-3-phenyl-6-oxoverdazyl $\quad(2[6,6] c)$. Crude product was purified by column chromatography $\left(\mathrm{SiO}_{2}\right.$, $\mathrm{CH}_{2} \mathrm{Cl}_{2}$ /petroleum ether $7: 1$ gradient $\left.1: 0\right)$ followed by recrystallization (AcOEt/ $\mathrm{CH}_{2} \mathrm{Cl}_{2}, 1: 4$ and $\mathrm{CH}_{3} \mathrm{CN} ; 4 \times$ ) to yield $170 \mathrm{mg}$ (75\%) as green-grey crystals: IR $(\mathrm{KBr}) \nu 1740(\mathrm{C}=\mathrm{O}), 1695,1606$, 1510 (C=C), 1251 (C-O), 1204, 1168, 1144 (C-F), 1073 (C-O) $\mathrm{cm}^{-1}$; MALDI-MS (m/z): $1375.4\left(100,[\mathrm{M}-\mathrm{CO}]^{+}\right)$. Anal. calcd for $\mathrm{C}_{58} \mathrm{H}_{45} \mathrm{~F}_{26} \mathrm{~N}_{4} \mathrm{O}_{7}$ : C, 49.62; H, 3.23; N, 3.99. Found: C, 49.42; H, $3.31 ; \mathrm{N}, 3.78$.

1,5-Bis $\{4-[4-(7,7,8,8,9,9,10,10,11,11,12,12,12$-tridecafluorododecyloxy)benzoyloxy]phenyl\}-3-(3-fluorophenyl)-6-oxoverdazyl $(2[6,6] d)$. Crude product was purified by column chromatography $\left(\mathrm{SiO}_{2}, \mathrm{CH}_{2} \mathrm{Cl}_{2} /\right.$ petroleum ether $8: 1$ gradient $\left.1: 0\right)$ followed by recrystallization $\left(\mathrm{CH}_{3} \mathrm{CN} / \mathrm{AcOEt}, 3: 1 ; 3 \times\right)$ to yield $121 \mathrm{mg}(82 \%)$ as pink-red crystals: $\mathrm{IR}(\mathrm{KBr}) \nu 1734(\mathrm{C}=\mathrm{O}), 1691,1607,1511(\mathrm{C}=$ C), 1258 (C-O), 1206, 1167, 1145 (C-F), 1071 (C-O) cm ${ }^{-1}$; MALDI$\operatorname{MS}(m / z)$ : $1393.0\left(100,[\mathrm{M}-\mathrm{CO}]^{+}\right)$. Anal. calcd for $\mathrm{C}_{58} \mathrm{H}_{44} \mathrm{~F}_{27} \mathrm{~N}_{4} \mathrm{O}_{7}$ : C, 48.99; H, 3.12; N, 3.94. Found: C, 48.85; H, 3.09; N, 3.66.

Preparation of acid chlorides $4[\mathrm{~m}, \mathrm{n}]$. A solution of 4 substituted benzoic acid ${ }^{\mathbf{1 6}}(0.57 \mathrm{mmol})$ and $\mathrm{SOCl}_{2}(4.5 \mathrm{~mL})$ was refluxed for $20 \mathrm{~min}$. Excess thionyl chloride was removed under vacuum. The remaining precipitate was dissolved in $\operatorname{dry} \mathrm{CH}_{2} \mathrm{Cl}_{2}$, the solvent was evaporated, and the procedure was repeated 2 times to remove traces $\mathrm{SOCl}_{2}$. The resulting colorless solid was dried under vacuum until no more odor of $\mathrm{SOCl}_{2}$ was detected, and used immediately for the subsequent esterification reaction.

\section{Acknowledgements}

This work was supported by the National Science Center (2013/ 09/B/ST5/01230 and 2014/13/B/ST5/04525). We thank Dr Hirosato Monobe of AIST, Japan for performing photoconductivity experiments, and Dr Jadwiga Szydłowska for assistance with VTEPR measurements.

\section{References}

1 R. Tamura, Y. Uchida and K. Suzuki, in Handbook of Liquid Crystals, J. W. Goodby, P. J. Collings, T. Kato, C. Tschierske, H. F. Gleeson and P. Raynes, ed. Wiley-VCH, Weinheim, 2014, vol. 8, pp. 837-864.

2 P. Ravat, T. Marszalek, W. Pisula, K. Müllen and M. Baumgarten, J. Am. Chem. Soc., 2014, 136, 12860-12863.
3 Stable radicals: fundamentals and applied aspects of oddelectron compounds, ed. R. G. Hicks, John Wiley \& Sons, Chichester, 2010.

4 A. Jankowiak, D. Pociecha, H. Monobe, J. Szczytko, Ż. Dębska, J. Romański and P. Kaszyński, Phosphorus, Sulfur Silicon Relat. Elem., 2013, 188, 418-426.

5 A. Jankowiak, D. Pociecha, H. Monobe, J. Szczytko and P. Kaszyński, Chem. Commun., 2012, 48, 7064-7066.

6 A. Jankowiak, D. Pociecha, J. Szczytko and P. Kaszyński, Liq. Cryst., 2014, 41, 1653-1660.

7 A. Jankowiak, D. Pociecha, J. Szczytko, H. Monobe and P. Kaszyński, J. Am. Chem. Soc., 2012, 134, 2465-2468.

8 A. Jankowiak, D. Pociecha, J. Szczytko, H. Monobe and P. Kaszyński, J. Mater. Chem. C, 2014, 2, 319-324.

9 A. Jankowiak, D. Pociecha, J. Szczytko, H. Monobe and P. Kaszyński, Liq. Cryst., 2014, 41, 385-392.

10 M. Jasiński, D. Pociecha, H. Monobe, J. Szczytko and P. Kaszyński, J. Am. Chem. Soc., 2014, 136, 14658-14661.

11 S. Ciastek, M. Jasiński and P. Kaszyński, RSC Adv., 2015, 5, 33328-33333.

12 C. Tschierske, Top. Curr. Chem., 2012, 318, 1-108.

13 C. Tschierske, in Handbook of Liquid Crystals, ed. J. W. Goodby, P. J. Collings, T. Kato, C. Tschierske, H. F. Gleeson and P. Raynes, Wiley-VCH, Weinheim, 2014, vol. 5, pp. 1-43, and references therein.

14 R. Milcent, G. Barbier, S. Capelle and J.-P. Catteau, J. Heterocycl. Chem., 1994, 31, 319-324.

15 M. Jasiński, J. S. Gerding, A. Jankowiak, K. Gębicki, J. Romański, K. Jastrzębska, A. Sivaramamoorthy, K. Mason, D. H. Evans, M. Celeda and P. Kaszyński, J. Org. Chem., 2013, 78, 7445-7454.

16 S. Ciastek, K. Szymańska, P. Kaszyński and M. Jasiński, submitted.

17 For a recent indepth discussion of factors affecting EPR linewidth in paramagnetic liquid crystals see: A. K. Vorobiev, N. A. Chumakova, D. A. Pomogailo, Y. Uchida, K. Suzuki, Y. Noda and R. Tamura, J. Phys. Chem. B, 2014, 118, 1932-1942.

18 M. J. Frisch, G. W. Trucks, H. B. Schlegel, G. E. Scuseria, M. A. Robb, J. R. Cheeseman, G. Scalmani, V. Barone, B. Mennucci, G. A. Petersson, H. Nakatsuji, M. Caricato, X. Li, H. P. Hratchian, A. F. Izmaylov, J. Bloino, G. Zheng, J. L. Sonnenberg, M. Hada, M. Ehara, K. Toyota, R. Fukuda, J. Hasegawa, M. Ishida, T. Nakajima, Y. Honda, O. Kitao, H. Nakai, T. Vreven, J. A. Montgomery Jr, J. E. Peralta, F. Ogliaro, M. Bearpark, J. J. Heyd, E. Brothers, K. N. Kudin, V. N. Staroverov, R. Kobayashi, J. Normand, K. Raghavachari, A. Rendell, J. C. Burant, S. S. Iyengar, J. Tomasi, M. Cossi, N. Rega, J. M. Millam, M. Klene, J. E. Knox, J. B. Cross, V. Bakken, C. Adamo, J. Jaramillo, R. Gomperts, R. E. Stratmann, O. Yazyev, A. J. Austin, R. Cammi, C. Pomelli, J. W. Ochterski, R. L. Martin, K. Morokuma, V. G. Zakrzewski, G. A. Voth, P. Salvador, J. J. Dannenberg, S. Dapprich, A. D. Daniels, O. Farkas, J. B. Foresman, J. V. Ortiz, J. Cioslowski and D. J. Fox, Gaussian 09, Revision A.02, Gaussian, Inc., Wallingford CT, 2009. 